\title{
Physiological Response to the Stress Effect of Anesthesia and Surgery in Sheep and Goat
}

\author{
M. Abdel Fattah ${ }^{1}$, Nermeen A. Helmy ${ }^{2}$, S. S. Ibrahim² \\ ${ }^{I}$ Departmentof Surgery, Anesthesia and Radiology and ${ }^{2}$ Deptartment of Physiology, Faculty of \\ Veterinary Medicine, Beni-Suef University, Beni-Suef 62511, Egypt.
}

\begin{abstract}
The present study was established to evaluate and compare stress response to anesthesia as well as surgery in sheep and goat. For this purpose, 5 rams and 5 bucks underwent anesthesia alone followed a week later by anesthesia with rumenotomy. Serum cortisol levels as well as differential leucocytic count were assayed just prior to anesthesia ( 0 time) and then after 1, 2, 4, 6 and 24 hours post anesthesia. In the second experiment, blood samples were collected just prior to anesthesia ( 0 time) then after half an hour ( 0 time post rumenotomy) then after 1, 2, 4, 6 and 24 hours post completion of rumenotomy. Serum cortisol levels in both species increased significantly and reach its peak one hour following anesthesia $(3.31 \pm 0.17$ and $4.09 \pm 0.12$, respectively) which were higher than subsequent cortisol levels. In addition, Peak cortisol level in sheep obtained at 0 time post rumenotomy $(4.39 \pm 0.13)$ and 1 hour following rumenotomy in goat $(3.45 \pm 0.16)$. The significant increase in cortisol level persists for 6 hours and returns to normal level 24 hours following surgery.
\end{abstract}

Adaptation reactions or stress reactions represent a modification of ongoing physiological mechanisms that allow an animal to respond to stress stimuli with minimum alteration in homeostasis (Breazile 1988). Stress responses may include changes in feeding, behavior, hypertension, reproductive dysfunction, inefficient feed conversion, gastric and intestinal ulcers, electrolyte imbalance, endocrinological changes and immune deficiency (Alam and Dobson 1986).

The major stress alterations involve synchronized control of hypothalamic releasing hormones of ACTH and of catecholamines results in biochemical and physiologic manifestations of stress including increased secretion of cortisol from the adrenal cortex (Nockels, 1990). The activation of hypothalamus-pituitary-adrenal axis is mediated by a number of factors. An increased activity is observed following the administration of anesthetic substances. The studies upon the anaesthetic stress are numerous (Luna and Taylor, 1995 and Luna and Taylor 2001). Some of them refer to the immediate post anesthetic period whereas others emphasize on changes occurring during the anesthesia itself (Dinev et al., 1998).

Moreover, the influence of pain during surgical interventions is also well documented. The International association for the study of pain defines pain as an unpleasant sensory and emotional experience associated with real or potential tissue damage (Horstman et al., 2004). Pain causes suffering and contributes to complications such as increased stress response, prolonged recovery and increased morbidity (Lascelles et al., 1994).

It is well established that different animal species and even animals of the same species but different genetic background respond differently to the same stressor (Hall, 1998). Moreover, Caulkett. (2003) reported that sheep and goat respond somewhat differently to stress. Accordingly, the aim of present study is to evaluate and compare the stress response to anesthesia and/or surgery in both sheep and goat.

\section{Material and methods}

A total of ten male baladi healthy animals of both species; sheep and goat were used in this study ( 5 rams and 5 bucks). The average body weights were $41.4 \pm 5.71 \mathrm{~kg}$ and $18.6 \pm 2.05$ for rams and bucks, respectively. It is of interest to note that choosing males in the current study was to exclude the stress effect of estrus.

Preparation of animals. All animals were kept under observation for two weeks for clinical and laboratory examination and proved to be healthy and in good conditions. Feed was withheld 24 hours prior to anesthesia while water was withheld 12 hours before anesthesia.

Experimental design. This study was carried out through two separate and subsequent experiments as follows:

Experiment I. The experiment was designed to study the effect of anesthesia alone on cortisol 
level. Animals were anaesthetized by epidural nethod using xylazine hydrochloride $2 \%$ at a dose of $0.3 \mathrm{mg} / \mathrm{kg}$ body weight diluted in $4 \mathrm{ml}$ sterile physiological saline in addition to linear local infiltration anesthesia using xylocaine hydrochloride 2\% (Abdel - Fattah, 1999).

For determination of serum cortisol level as well as differential leucocytic count, blood samples were collected individually from jagular vein just prior to anesthesia (0 time) and then after 1, 2, 4, 6 and 24 hours post anesthesia.

Experiment II. The experiment was designed to study the effect of anesthesia and surgery on cortisol level.

One week following the first experiment, the same animals were used for carrying rumenotomy. For this purpose, the same anesthetics and the same technique mentioned in experiment I was used for rumenotomy. Rumenotomy was chosen as a model for surgical interference because it is frequent in both species.

Duration of rumenotomy in each animal was about half an hour.

Blood samples were collected for the same purposes just prior to anesthesia (0 time) then after half an hour ( 0 time post rumenotomy) then after 1, 2, 4, 6 and 24 hours post completion of rumenotomy.

Procedures. Serum was separated by centrifugation at 3000 r.p.m for 15 minutes and kept frozen at $-20^{\circ} \mathrm{C}$ for hormonal assay. For determination of serum cortisol level, cortisol ELISA kits (Immunospec Corporation, USA) was used.

For differential leucocytic count, blood films were prepared from each fresh sample and stained by giemsa stain.

Serum cortisol level and differential leucocytic count were statistically analyzed using one-way analysis of variance (ANOVA). P values $<0.05$ were considered statistically significant.

\section{Results}

There was significant increase in serum cortisol level 1 hour following anaesthesia in both sheep and goat $(4.1 \pm 0.12 \mu \mathrm{g} / \mathrm{dl}$ and $3.31 \pm$ $0.18 \mu \mathrm{g} / \mathrm{dl}$, respectively) versus $(1.6 \pm 0.17 \mu \mathrm{g} / \mathrm{dl}$ and $1.52 \pm 0.12 \mu \mathrm{g} / \mathrm{dl}$, respectively) at 0 time (Table 1). The significant increase in cortisol level persists for 6 hours and returns to normal level 24 hours following anaesthesia.

Results in Table (2) show that there was significant increase in serum cortisol level at 0 time post surgery in both species. Peak cortisol level in sheep obtained at 0 time post surgery $(4.39 \pm 0.13 \mu \mathrm{g} / \mathrm{dl})$ and while in goats it was 1 hour following rumenotomy $(3.45 \pm 0.16 \mu \mathrm{g} / \mathrm{dl})$. The significant increase in cortisol level persists for 6 hours and returns to normal level 24 hours following anaesthesia in both species.

Table (1): Serum cortisol level $(\mu \mathrm{g} / \mathrm{dl})$ following anaesthesia in sheep and goat (Mean \pm Standard Error).

\begin{tabular}{lll}
\hline Time & Sheep & Goat \\
\hline 0 time (pre-anesthesia) & $1.6 \pm 0.17^{\mathrm{a}}$ & $1.52 \pm 0.12^{\mathrm{a}}$ \\
$\mathbf{1}$ hour (post-anesthesia) & $4.1 \pm 0.12^{\mathrm{b}}$ & $3.31 \pm 0.18^{\mathrm{b}}$ \\
$\mathbf{2}$ hours (post-anesthesia) & $3.9 \pm 0.17^{\mathrm{bc}}$ & $2.9 \pm 0.04^{\mathrm{c}}$ \\
$\mathbf{4}$ hours (post-anesthesia) & $3.56 \pm 0.22^{\mathrm{c}}$ & $2.72 \pm 0.09^{\mathrm{c}}$ \\
$\mathbf{6}$ hours (post-anesthesia) & $2.37 \pm 0.21^{\mathrm{d}}$ & $2.15 \pm 0.06^{\mathrm{d}}$ \\
$\mathbf{2 4}$ hours (post-anesthesia) & $1.6 \pm 0.25^{\mathrm{a}}$ & $1.54 \pm 0.16^{\mathrm{a}}$ \\
\hline
\end{tabular}

In the same column, values having different letters differ significantly ( $\mathrm{P}$ values $<0.05$ ).

Table (2): Serum cortisol level $(\mu \mathrm{g} / \mathrm{dl})$ following anesthesia and surgery in sheep and goat (Mean \pm Standard Error).

\begin{tabular}{lll}
\hline Time & Sheep & Goat \\
\hline 0 time (pre rumenotomy) & $1.54 \pm 0.14^{\mathrm{a}}$ & $1.48 \pm 0.13^{\mathrm{a}}$ \\
0 time (post rumenotomy) & $4.39 \pm 0.13^{\mathrm{b}}$ & $2.78 \pm 0.13^{\mathrm{b}}$ \\
1 hour (post rumenotomy) & $4.32 \pm 0.14^{\mathrm{b}}$ & $3.45 \pm 0.16^{\mathrm{c}}$ \\
$\mathbf{2}$ hours (post rumenotomy) & $3.81 \pm 0.12^{\mathrm{b}}$ & $2.94 \pm 0.07^{\mathrm{b}}$ \\
$\mathbf{4}$ hour (post rumenotomy) & $3.72 \pm 0.18^{\mathrm{b}}$ & $2.73 \pm 0.19^{\mathrm{b}}$ \\
6 hours (post rumenotomy) & $2.55 \pm 0.29^{\mathrm{c}}$ & $2.11 \pm 0.1^{\mathrm{d}}$ \\
$\mathbf{2 4}$ hours (post rumenotomy) & $1.53 \pm 0.14^{\mathrm{a}}$ & $1.7 \pm 0.16^{\mathrm{a}}$ \\
\hline
\end{tabular}

In the same column, values having different letters differ significantly (P values $<0.05$ ). 
Results in (Tables 3, 4, 5 and 6) show that there was significant increase in neutrophil $\%$ and significant decrease in lymphocyte $\%$ which were related to peak cortisol level 1 hour following anaesthesia and/or surgery in goat. On the other hand, in sheep, significant increase in neutrophils and decrease in lymphocyte $\%$ observed at 0 time post surgery and existed up to 4 hours.

Table (3): Differential leucocytic count in sheep following anaesthesia (Mean \pm Standard Error).

\begin{tabular}{lllll}
\hline Time & Neutrophils (\%) & Lymphocytes (\%) & Eosinophils (\%) & Monocytes (\%) \\
\hline 0 time (pre-anesthesia) & $35.8 \pm 1.58^{\mathrm{a}}$ & $57.8 \pm 1.16^{\mathrm{a}}$ & $2.6 \pm 0.40$ & $3.8 \pm 0.58$ \\
1 hour (post-anesthesia) & $46.6 \pm 1.63^{\mathrm{b}}$ & $47.2 \pm 0.97^{\mathrm{b}}$ & $3.2 \pm 0.37$ & $3.8 \pm 0.58$ \\
2 hours (post-anesthesia) & $48.4 \pm 1.08^{\mathrm{b}}$ & $47.0 \pm 1.58^{\mathrm{b}}$ & $2.8 \pm 0.37$ & $3.7 \pm 0.49$ \\
$\mathbf{4}^{\mathrm{b}}$ hours (post-anesthesia) & $46.8 \pm 1.46^{\mathrm{b}}$ & $47.6 \pm 1.21^{\mathrm{b}}$ & $2.8 \pm 0.35$ & $3.2 \pm 0.58$ \\
6 hours (post-anesthesia) $^{\mathrm{b}}$ & $37.6 \pm 1.72^{\mathrm{a}}$ & $55.4 \pm 1.86^{\mathrm{a}}$ & $3.0 \pm 0.32$ & $4.0 \pm 0.45$ \\
24 hours (post-anesthesia) & $36.0 \pm 1.87^{\mathrm{a}}$ & $57.8 \pm 1.74^{\mathrm{a}}$ & $3.0 \pm 0.45$ & $3.6 \pm 0.24$ \\
\hline
\end{tabular}

In the same column, values having different letters differ significantly ( $\mathrm{P}$ values $<0.05$ ).

Table (4): Differential leucocytic count in goat following anaesthesia (Mean \pm Standard Error).

\begin{tabular}{lllll}
\hline Time & Neutrophils (\%) & Lymphocytes (\%) & Eosinophils (\%) & Monocytes (\%) \\
\hline 0 time (pre-anesthesia) & $38.2 \pm 1.16^{\mathrm{a}}$ & $56.4 \pm 1.29^{\mathrm{a}}$ & $2.2 \pm 0.19^{\mathrm{a}}$ & $3.2 \pm 0.38$ \\
$\mathbf{1}$ hour (post-anesthesia) & $46.4 \pm 0.9^{\mathrm{b}}$ & $47.4 \pm 1.32^{\mathrm{b}}$ & $2.6 \pm 0.25^{\mathrm{ab}}$ & $3.4 \pm 0.24$ \\
2 hours (post-anesthesia) & $39.4 \pm 0.9^{\mathrm{a}}$ & $53.6 \pm 1.10^{\mathrm{a}}$ & $3.4 \pm 0.24^{\mathrm{bc}}$ & $3.6 \pm 0.23$ \\
$\mathbf{4}$ hours (post-anesthesia) & $38.6 \pm 1.36^{\mathrm{a}}$ & $54.4 \pm 1.12^{\mathrm{a}}$ & $3.2 \pm 0.38^{\mathrm{bc}}$ & $3.8 \pm 0.37$ \\
$\mathbf{6}^{\mathrm{ac}}$ hours (post-anesthesia) & $36.8 \pm 1.28^{\mathrm{a}}$ & $57.2 \pm 4.10^{\mathrm{a}}$ & $3.0 \pm 0.32^{\mathrm{abc}}$ & $3.8 \pm 0.19$ \\
$\mathbf{2 4}^{\mathrm{a}}$ hours (post-anesthesia) & $37.4 \pm 1.63^{\mathrm{a}}$ & $55.4 \pm 3.80^{\mathrm{a}}$ & $3.6 \pm 0.25^{\mathrm{c}}$ & $4.0 \pm 0.32$ \\
\hline
\end{tabular}

In the same column, values having different letters differ significantly ( $\mathrm{P}$ values $<0.05$ ).

Table (5): Differential leucocytic count in sheep following surgery (Mean \pm Standard Error).

\begin{tabular}{lllll}
\hline Time & Neutrophils (\%) & Lymphocytes (\%) & Eosinophils (\%) & Monocytes (\%) \\
\hline 0 time pre rumenotomy & $35.8 \pm 1.43^{\mathrm{a}}$ & $57.4 \pm 1.53^{\mathrm{a}}$ & $2.8 \pm 0.38$ & $3.6 \pm 0.51$ \\
0 time post rumenotomy & $46.2 \pm 1.77^{\mathrm{b}}$ & $47.6 \pm 1.86^{\mathrm{b}}$ & $2.6 \pm 0.25$ & $3.6 \pm 0.51$ \\
1 hour (post rumenotomy) & $48.8 \pm 1.16^{\mathrm{b}}$ & $44.2 \pm 1.53^{\mathrm{b}}$ & $3.0 \pm 0.32$ & $4.0 \pm 0.32$ \\
2 hours (post rumenotomy) & $45.4 \pm 1.43^{\mathrm{b}}$ & $49.2 \pm 1.39^{\mathrm{bc}}$ & $2.2 \pm 0.37$ & $3.2 \pm 0.37$ \\
$\mathbf{4}^{\mathrm{b}}$ hours (post rumenotomy) & $46.0 \pm 2.70^{\mathrm{b}}$ & $48.0 \pm 2.66^{\mathrm{b}}$ & $2.4 \pm 0.24$ & $3.6 \pm 0.53$ \\
6 hours (post rumenotomy) $^{\mathrm{b}}$ & $39.8 \pm 1.38^{\mathrm{a}}$ & $54.2 \pm 1.35^{\mathrm{ac}}$ & $3.0 \pm 0.45$ & $3.4 \pm 0.24$ \\
24 hours (post rumenotomy) & $36.2 \pm 1.59^{\mathrm{a}}$ & $58.0 \pm 1.48^{\mathrm{a}}$ & $2.4 \pm 0.25$ & $3.6 \pm 0.50$ \\
\hline
\end{tabular}

In the same column, values having different letters differ significantly ( $\mathrm{P}$ values $<0.05$ ).

Table (6): Differential leucocytic count in goat following surgery (Mean \pm Standard Error).

\begin{tabular}{lllll}
\hline Time & Neutrophils (\%) & Lymphocytes (\%) & Eosinophils (\%) & Monocytes (\%) \\
\hline 0 time pre rumenotomy & $38.4 \pm 1.36^{\mathrm{a}}$ & $56.0 \pm 1.38^{\mathrm{a}}$ & $2.4 \pm 0.25$ & $3.2 \pm 0.35$ \\
0 time post rumenotomy & $40.2 \pm 1.24^{\mathrm{a}}$ & $54.0 \pm 1.22^{\mathrm{a}}$ & $2.6 \pm 0.39$ & $3.2 \pm 0.37$ \\
$\mathbf{1}$ hour (post rumenotomy) & $46.8 \pm 1.46^{\mathrm{b}}$ & $46.6 \pm 1.59^{\mathrm{b}}$ & $2.6 \pm 0.38$ & $4.0 \pm 0.31$ \\
2 hours (post rumenotomy) & $39.8 \pm 1.39^{\mathrm{a}}$ & $53.6 \pm 1.03^{\mathrm{a}}$ & $2.8 \pm 0.37$ & $3.8 \pm 0.36$ \\
$\mathbf{4}$ hours (post rumenotomy) & $38.6 \pm 2.06^{\mathrm{a}}$ & $55.6 \pm 2.25^{\mathrm{a}}$ & $2.6 \pm 0.24$ & $3.2 \pm 0.37$ \\
$\mathbf{6}^{\mathrm{a}}$ hours (post rumenotomy) & $38.0 \pm 1.37^{\mathrm{a}}$ & $55.0 \pm 2.02^{\mathrm{a}}$ & $3.0 \pm 0.32$ & $4.0 \pm 0.4$ \\
$\mathbf{2 4}^{\mathrm{a}}$ hours (post rumenotomy) & $37.4 \pm 1.63^{\mathrm{a}}$ & $56.6 \pm 1.5^{\mathrm{a}}$ & $2.8 \pm 0.37$ & $3.2 \pm 0.32$ \\
\hline
\end{tabular}

In the same column, values having different letters differ significantly ( $\mathrm{P}$ values $<0.05)$.

\section{Discussion}

Cortisol is a steroid hormone belonging to class of steroids called glucocorticoids. The stress response is characterized by increased secretion of pituitary hormones and activation of the sympathetic nervous system (Kehlet, 1991 and Desborough and Hall, 1993). Anterior pituitary hormone secretion is stimulated by hypothalamic releasing factors (Lyons and Meeran, 1997). The pituitary synthesizes corticotrophin or adrenocorticotrophic hormone (ACTH) which stimulates release of corisol from adrenal cortex. Plasma cortisol level is the most frequently used marker for different kinds of stress-induced reactions such as operative procedures and anesthesia (Ram et al., 2005).

The obtained results, in the present study, revealed that the normal average levels of cortisol in sheep and goat $(1.6 \pm 0.17,1.54 \pm$ 0.14 and $1.52 \pm 0.12,1.48 \pm 0.13$, respectively) 
come in accordance with results of previous studies (Hughan et al., 2001 and Carroll et al., 2007).

It can be also noticed that cortisol levels of the two experimental animals are quiet similar. Nevertheless, bearing in mind, the average body weight of animals used in the current work (41.4 $\pm 5.71 \mathrm{~kg}$ and $18.6 \pm 2.05$, for sheep and goat respectively) it can be thought that the secretory activity of adrenal glands is relatively higher in sheep than in goats.

It is well established that different animal species and even animals of the same species but different genetic background respond differently to the same stressor (Hall, 1998). Therefore, it was thought of interest to assess if sheep and goat would respond differently to the stressful stimulus. Moreover, measurement of cortisol is valuable in stress research because cortisol shows a graduated response depending on the severity of the stressor.

Results of current study revealed that anesthesia in both sheep and goat induced significant increase in serum cortisol level 1 hour following application that persists for 6 hours and returns to normal level after 24 hours. Similarly, in goat, Carroll et al., (2007) reported that cortisol was elevated at 60 minutes compared to baseline. The authors suggested that the increase was related to the acute stress of rapid epidural administration of morphine and not to the pharmacologic effect of the drug itself. In sheep, Hughan et al., (2001) reported that plasma cortisol concentrations increased significantly during the second hour of anesthesia.

Under the conditions of the present study, it is clearly obvious that the significantly increased level of cortisol under the effect of anesthesia extended up to six hours post-anestheia in both species. The available literature did not include similar results. Therefore, it is so difficult to assess a conclusive or reliable reason for the obtained results in the preset study. However, in a previous study it was noticed that plasma cortisol level increased significantly after the start of anesthesia and surgery in gravid ewe and the hormone level returned to its baseline level after 48 hours (Erenburg, 1982).

Results in table 2 showed that there was significant increase in serum cortisol level at 0 time post rumenotomy in both species. Peak cortisol level obtained at 0 time and 1 hour post rumenotomy in sheep and goat, respectively. The significant increase in cortisol level persists for 6 hours and returns to normal level 24 hours following operation. These findings are consistent with previous report of Hughan et al., (2001) that revealed significant increase in cortisol level during the second hour post operation in sheep which decreased 4 hours post operation. Moreover, marked elevation of plasma cortisol and $\beta$-endorphin occurred between 5 and $15 \mathrm{~min}$ after the operation in sheep and goat (Fell and Shutt, 1989).

The increase in serum cortisol level following operation is mainly associated with trauma and pain resulted from surgery. In this respect, Le Blanc-Louvry et al., (2000); Ntonas et al., (2012) have found out that postoperative pain levels are associated with increased cortisol concentration, suggesting the importance of hormones in functional recovery postoperatively. However, several studies concluded that deep anesthesia is related with less postoperative pain (Ntonas et al., 2012). That may discuss the cause of the relative similarity in serum cortisol level following rumenotomy and that obtained following anesthesia in the first experiment.

It was expected that the combined effect of both anesthesia and surgery would induce stronger response on cortisol level, but it was not the case in the two species. However, it can be suggested that the effect of anesthestics on CNS and the subsequent effect on cortisol secretio from adrenal cortex would predominate tissue damage effect of incision and surgery. Absence of sensation and loss of feeling pain under the influence of anesthesia may support this opinion.

Leukocyte profiles are particularly useful in the field of conservation physiology because they are altered by stress and can be directly related to stress hormone levels (Dhabhar et al., 1996). Current results revealed that the increased concentrations of cortisol, within 4 hours and 1 hour post anesthesia and surgery in sheep and goat, respectively, is accompanied with increase in neutrophil \% and decrease in lymphocyte \%. The findings are in concomitance with those of Kannan et al., (2000), who reported an increased percentage of neutrophils and decreased lymphocytes due to transportation stress.

The changes in leucocyte profile brought on by stress or glucocorticoid treatment include increase in numbers of neutrophils (neutrophilia) and decrease in lymphocyte numbers (lymphopenia or lymphocytopenia). The mechanism underlying the effect of stress hormones on leukocyte profiles has been welldocumented in biomedical studies of mammals 
( Ottaway and Husband 1994 and Brenner et al., 1998). Stress-induced reductions in circulating lymphocyte numbers are not due to large-scale destruction of cells but to redistribution of lymphocytes from the blood to other body compartments (Dhabhar, 2002). In response to glucocorticoids, circulating lymphocytes adhere to the endothelial cells that line the walls of blood vessels and subsequently undergo transmigration from circulation into other tissues including lymph nodes, spleen, bone marrow and skin where they are sequestered (Fauci, 1975 and Dhabhar, 2002). This exodus of lymphocytes from the blood causes a significant reduction in their circulating numbers. In contrast, glucocorticoids also stimulate an influx of neutrophils into the blood from bone marrow and attenuate the egress of neutrophils from the blood to other compartments (Bishop et al., 1968). These changes are thought to ensure that the different types of cells are routed to where they are needed during the stress response (Dhabhar et al., 1994 and Dhabhar et al., 1996).

From results of the current study, it can be concluded that serum cortisol level in sheep and goat was relatively similar. In addition, anesthesia alone and anesthesia with surgery induced significant increase in serum cortisol level in both species that returned to baseline levels after 24 hours. Moreover, stress response in both species was similar to some extent.

It is recommended to study the effect of different anesthestics as well as different surgical techniques on cortisol level and stress response in both species.

\section{References}

Abdel -Fattah, M. (1999): The goat as a model for experimental surgery. Ph.D. thesis, Fac. Vet. Med., Cairo Univ, Beni Suef branch.

Alam, M. G. and Dobson, H. (1986): Effect of various veterinary procedures on plasma concentrations of cortisol, luteinizing hormone and prostaglandin E2 metabolite in the cow. Vet Rec, 118: 7.

Bishop, C. R.; Athens, J. W.; Boggs, D. R.; Warner, H. R.; Cartwright, G. E. and Wintrobe, M. M. (1968): Leukokinetic studies XIII. A non-steady-state kinetic evaluation of the mechanism of cortisone-induced granulocytosis. J Clinic Invest, 47: 249-260.

Breazile, J. E. (1988): The physiology of stress and its relationship to mechanisms of disease and therapeutics. Vet. Clin. North. Am: Food Anim. Pract., 4: 441-480.

Brenner, S. E.; Chothia, C. and Hubbard, T. J. (1998): Assessing sequence comparison methods with reliable structurally identified distant evolutionary relationships. Proc Natl Acad Sci USA, 95: 6073-6078.

Carroll, G. L.; Nora, S.; Matthews, M. A.; Crist, S.; Champney, T.H. and Hartsfield, S. M. (2007):Behavioral, physiologic, and stress- related hormonal and metabolic responses to intravenous and epidural morphine in goats. Intern. J Appl Res Vet Med, 5: 101-108.

Caulkett, N., (2003): Anaesthesia of ruminants. Large Anim. Vet rounds.

Desborough, J. P. and Hall, G. M. (1993): Endocrine response to surgery. Anaesthesia Rev. 2: $131-48$.

Dinev, D.; Georgiev, P.; Hubenov, H.; Zlateva, N. and Bakalov, D. (1998): Changes in some hormonal parameters in halotane anaesthetized horses. Bul J Vet Med, 1: 33-40.

Dhabhar, F. S. (2002): A hassle a day may keep the doctor away: stress and the augmentation of immune function. Integrative and Comparative Biology, 42: 556-564.

Dhabhar, F. S.; Miller, A. H.; Stein, M.; Mcewen, B. S. and Spencer, R. L. (1994): Diurnal and stress-induced changes in distribution of peripheral blood leukocyte subpopulations. Brain Behav Immun, 8: 66.

Dhabhar, F. S.; Miller, A. H.; Stein, M.; Mcewen, B. S. and Spencer, R. L. (1996): Stress-Induced Changes in Blood Leukocyte Distribution Role of Adrenal Steroid Hormones. J Immunol, 157: 1638-1644.

Erenberg, A. (1982): Effect of epidural anesthesia and surgery on serum thyroid hormone and cortisol levels in the gravid ewe. Dev Pharmacol Ther. 4(1-2):81-88.

Fauci, A. S. (1975): Mechanisms of corticosteroid action on lymphocyte subpopulations 1. Redistribution of circulating T-lymphocytes and Blymphocytes to bone marrow. Immunology: 28: 669-680.

Fell, L. ad Shutt, D. (1989): Behavioural and hormonal responses to acute surgical stress. Applied Anim. Behav. Sci. 22: 283-294.

Hall, F. S. (1998): Social deprivation of neonatal, adolescent, and adult rats has distinct neurochemical and behavioral consequences. Crit Rev Neurobiol, 12:129-162.

Horstman, C. L.; Conzeminus, M. G.; Evans, R. and Gordon, W. J. (2004): Assessing the efficacy of perioperative oral carprofen after cranial cruciate surgery using noninvasive, objective pressure platform gait analysis. Vet. Surg., 33: 286-292.

Hughan, S. C.; Loose, M.; Caddy, D. I.; Canny, B. I. and Young, R. (2001): Combined xylazíne and ketamine as an analgesic regimen in sheep. Aust Vet J 79: 207-211.

Kannan, G.; Terrill, T. H.; Kouakou, B. Gazal, O. S.; Gelaye, S.; Amoah, E. A. and Samake, S. (2000): Transportation of goats: Effects on physiological stress responses and live weight loss. J. Anim. Sci., 78: 14501457.

Kehlet, H. (1991): Neurohumoral response to surgery and pain inman. Proc 6th World Cong on Pain., 35-40. Elsevier, Amsterdam, The Netherlands.

Lascelles, B. D.; Butterworth, S. J. and Waterman, A. E. (1994): Postoperative analgesic and sedative effects of carprofen and pethidine in dogs. Vet Rec, 134: 187-191.

Le Blanc-Louvry, I.; Coquerel, A.; Koning, E.; Maillot, C. and Ducrotté, P. (2000): Operative stress response is reduced after laparoscopic compared to open cholecystectomy: the relationship with postoperative pain and ileus. Dig. Dis. Sc., 45: 1703-1713.

Luna, S. and Taylor, P., (1995): Pituitary-adrenal activity and opioid release in ponies during thiopentone/halothane anaesthesia. Res. Vet. Sci., 58: 35-41.

Luna, S. and Taylor, P. (2001): Cardiorespiratory and endocrine effects of endogenous opioid antagonism by naloxone in ponies anaesthetised with halothane. Res Vet Sci, 70: 95-100.

Lyons, F. M. and Meeran, K. (1997): The physiology of the endocrine system. Int Anesthesiol Clin, 35: 1-21.

Nockels, C. F. (1990) : Mineral alterations associated with 
stress, trauma, and infection and the effect on immunity. Cont Educ Pract Vet, 12: 1133-1139.

Ntonas, G.; Vogiatzaki, T.; Chatziioakeimidis, C. Chloropoulou, P. and Iatrou, C. (2012): Close correlation of cortisol with pain intensity and Aldrete score in immediate post anesthesia period. Aristotle Univ. Med J, 39: $145-159$.
Ottawav, C. A. Husband, A. J. (1994): The influence of neuroendocrine oathways'on lymphocyte migration: Immunol Today 15:51 1-517.'

Ram, E.; Vishne, T. H.; Weinstein, T.; Beilin, B. and Dreznik, Z. (2005): General anesthesia for surgery influences melatonin and cortisol levels. World J. Surg., 29: $826-829$. 